\title{
ROBOT LINE TRACKING UNTUK EDUKASI DI SEKOLAH SMP SANTO ANDREAS JAKARTA BARAT
}

\author{
Hadian Satria Utama ${ }^{1}$ dan Joni Fat ${ }^{2}$
}

\author{
${ }^{1}$ Program Studi Teknik Elektro, Universitas Tarumanagara Jakarta \\ ${ }^{2}$ Program Studi Teknik Elektro, Universitas Tarumanagara Jakarta \\ Email: jonif@ft.untar.ac.id
}

\begin{abstract}
Line tracking robot is a robot that could move by following a black line or a white line as a border. The robot consists of two motors with gearboxes, robot body which is built by using a $5 \mathrm{~mm}$ acrylic, breadboard, microcontroller, line tracking sensor and ball caster. Line tracking sensor will give an input to microcontroller to process. Microcontroller will activate motor according to conditions from the sensor. Robot will move forward if it detects a white line and will stop if it detects a black line. The purpose of building this line tracking robot is to educate Santo Andreas Junior High Schooler. It intended to flourish talents in robotics. The method that uses in this education is with extracurricular program. This program will be carried out in every two weeks throughout a semester with total of eight courses. The teachers are students from Electrical Engineering of Universitas Tarumanagara. These courses will teach the Junior High Schooler how to build line tracking robot and the foundation of robotics itself. It should need a longer duration in each session so the modules and learning targets could be finished well. This program also need more lecturers. It is caused by the ratio between students and lecturers is 21:4. The learning modules need a lecturer to focus only on a small team. Enthusiasm from students in this learning project is very high, so this could be proposed to become a subject in the curriculum of Junior High School of Santo Andreas.
\end{abstract}

Keywords: education, line tracking robot, microcontroller, sensor.

\begin{abstract}
ABSTRAK
Robot line tracking merupakan robot yang dapat bergerak mengikuti lintasan berupa garis hitam sebagai pembatas dan jalur berwarna putih. Robot ini terdiri atas dua buah motor beserta gearbox dan roda, badan robot yang terbuat dari akrilik 5mm, breadboard, mikrokontroler, sensor line track, dan ball caster. Sensor line track akan memberikan input kepada mikrokontroler untuk diproses. Mikrokontroler akan menggerakan motor sesuai dengan kondisi dari sensor. Robot akan berjalan ketika mendeteksi warna putih dan akan berhenti ketika mendeteksi warna hitam. Tujuan dibuatnya robot line tracking ini adalah untuk mengedukasi siswa smp Santo Andreas serta menggali minat dan bakat siswa di bidang robotika. Metode pelaksanaan pemberian edukasi ini melalui program ekstrakurikuler. Kegiatan pemberian edukasi ini berlangsung dua minggu sekali selama satu semester dengan total 8 pertemuan. Tenaga pengajar ekstrakurikuler robotika adalah mahasiswa Teknik Elektro Universitas Tarumanagara. Materi yang diajarkan adalah cara membuat robot line tracking dan juga dasar-dasar dari ilmu robotika itu sendiri. Diperlukan durasi lebih panjang pada setiap pertemuan dari kegiatan ekstrakurikuler sehingga materi dan target pengajaran yang diberikan dapat tersampaikan dengan baik, juga diperlukan tambahan pengajar. Hal ini dikarenakan rasio perbandingan peserta dan pengajar adalah sebesar 21:4, dan materi yang diajarkan memerlukan pendampingan lebih dari pengajar. Antusiasme peserta kegiatan ekstrakurikuler robotika line tracking ini sangat tinggi, sehingga dapat dijadikan mata pelajaran dalam kurikulum pendidikan di Sekolah SMP Santo Andreas.
\end{abstract}

Kata Kunci: edukasi, mikrokontroler, robot line tracking, sensor.

\section{PENDAHULUAN}

\section{Analisis Situasi}

Teknologi pada zaman sekarang ini berkembang sangat cepat. Manusia sangat bergantung pada teknologi. Hal ini yang membuat teknologi menjadi kebutuhan dasar setiap orang, dari orang tua hingga siswa di sekolah. Teknologi khususnya di bidang robotika sangatlah penting untuk menjadi bahan edukasi siswa di sekolah. Ilmu Robotika sendiri adalah ilmu yang mempelajari tentang pengaplikasian robotika dalam kehidupan sehari-hari (Nalwan, 2012). Robot didesain dan disesuaikan dengan kebutuhan sehingga tercipta desain yang ekonomis (Romadhon \& Fuad, 2013).

SMP Santo Andreas bekerja sama dengan Teknik Elektro Universitas Tarumanagara untuk mengadakan ekstrakulikuler di bidang robotika. SMP santo Andreas beralamat di Jl. Kedoya Utara 
Kedoya Selatan Kebon Jeruk Jakarta Barat DKI Jakarta, RT.1/RW.4, Kedoya Utara, Kec. Kb. Jeruk, Kota Jakarta Barat, Daerah Khusus Ibukota Jakarta.

\section{Gambar 1}

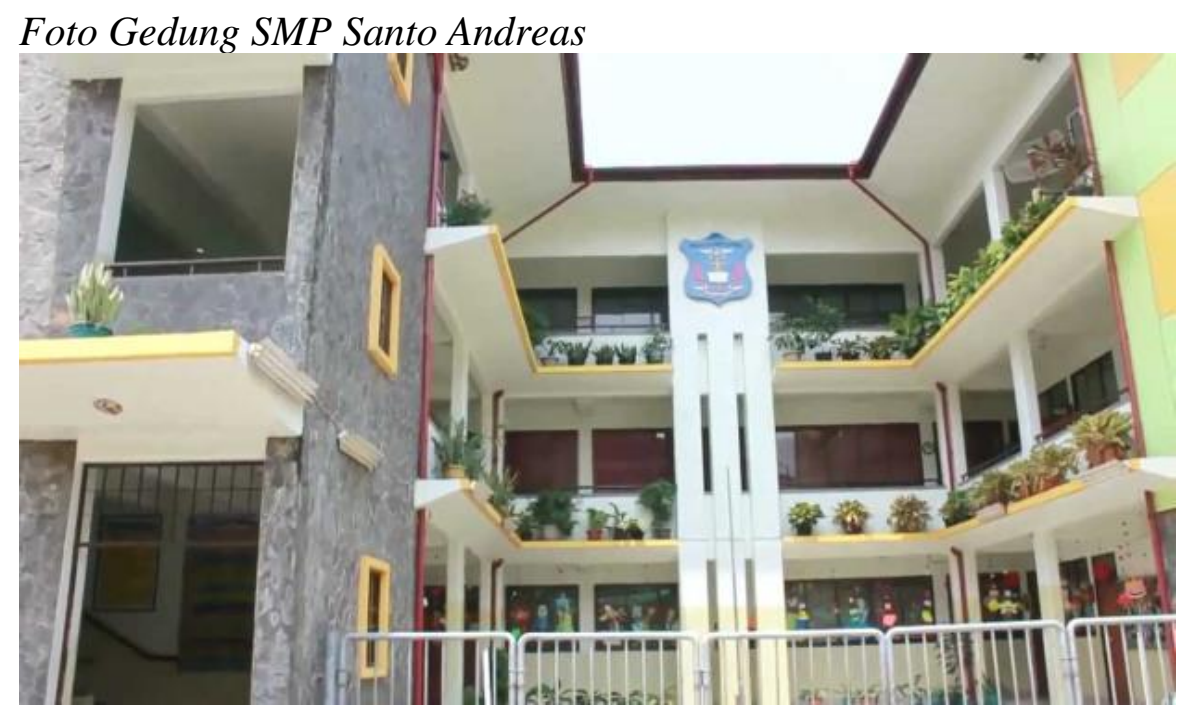

Sekolah SMP Santo Andreas memiliki total siswa sebanyak 107 orang. Akan tetapi, jumlah siswa yang mengikuti kegiatan ekstrakurikuler ini dibatasi hanya sebanyak 21 orang saja. Hal ini dikarenakan keterbatasan sarana dan prasarana yang ada, serta kesepakatan antara kedua belah pihak. Mata Pelajaran mengenai robotika belum pernah diadakan sebelumnya di SMP Santo Andreas. Sekolah SMP Santo Andreas juga sebelumnya telah menyewa tenaga pengajar ekstrakurikuler di bidang robotika untuk mengedukasi siswa SMP Santo Andreas tentang robotika. Akan tetapi, biaya yang dikeluarkan dirasa terlalu tinggi, dan materi yang diajarkan kurang tepat dan efektif. Untuk itu, Teknik Elektro Universitas Tarumanagara memberikan solusi kepada SMP Santo Andreas untuk menjadi tenaga pengajar ekstrakurikuler Robotika.

Siswa sekolah SMP Santo Andreas perlu untuk mempelajari tentang robotika dan elektronika. Selain menambah wawasan, belajar tentang robotika dan elektronika juga dapat menumbuhkan minat dan menggali bakat dari siswa. Merakit dan memprogram robot dapat melatih kreativitas dan logika berpikir sehingga lebih kritis (Tridhonanto. 2010). Hal ini merupakan salah satu aspek penting untuk mempersiapkan generasi muda yang berkualitas.

Pengetahuan tentang robotika akan diberikan oleh mahasiswa Teknik Elektro sebagai pengajar ekstrakurikuler robotika di SMP Santo Andreas. Mahasiswa cocok sebagai pengajar karena rentang usia yang terpaut belum terlalu jauh. Ini akan membuat siswa lebih nyaman dan leluasa dalam belajar maupun bertanya. Juga ini merupakan latihan bagi mahasiswa untuk mempunyai keberanian di hadapan orang banyak dan mampu membagikan ilmu kepada orang lain. Dalam satu semester akan ada 8 pertemuan di mana di setiap pertemuan mempunyai hasil yang akan menunjang di pertemuan akhir untuk pembuatan robot line tracking.

\section{Permasalahan Mitra}

Berdasarkan analisis situasi di lingkungan mitra maka dapat diketahui permasalahan yaitu, dibutuhkan tenaga pengajar di bidang robotika dan elektronika untuk memberikan edukasi kepada siswa SMP yang mempunyai materi pengajarannya jelas dan efektif. Oleh karena itu, adanya program pengabdian kepada masyarakat, dengan didukung kompetensi bidang komputer dan robotika serta elektronika. 


\section{Solusi Permasalahan}

Solusi dari permasalahan SMP Santo Andreas adalah pemberian pengetahuan tentang robotika melalui program ekstrakurikuler selama satu semester yang akan diberikan oleh Universitas Tarumanagara dengan mahasiswa Teknik Elektro Universitas Tarumanagara sebagai pengajarnya. Program ekstrakurikuler ini dimulai pada tahun ajaran baru 2019/2020 di SMP Santo Andreas. Setiap dua minggu sekali akan ada empat orang mahasiswa Teknik Elektro yang akan menjadi pengajar ekstrakurikuler. Materi yang diajarkan merupakan dasar-dasar robotika yang akan menjadi penunjang untuk membuat robot line tracking. Di pertemuan terakhir sebagai puncak dari pemberian edukasi tentang robotika, robot line tracking ini akan diwujudkan.

Robot line tracking cocok untuk diajarkan kepada siswa SMP karena walaupun cukup sederhana, tetapi komponen-komponen penyusunnya lengkap dan mencakup dasar dari ilmu robotika (Jatmiko et al., 2012; Winarto \& Arifianto, 2011)[4] [5]. Tiap pertemuan akan ada target pencapaian yang dicapai oleh siswa dan satu pertemuan berkesinambungan dengan pertemuan berikutnya. Siswa juga didorong untuk berkreasi dengan design dari robot line tracking mereka, baik secara design fisik maupun design elektroniknya. Selain praktek pembuatan robot, siswa juga diajarkan sedikit teori tentang alat-alat yang digunakan pada setiap pertemuan agar siswa dapat mengerti cara kerja dari setiap alat dan bahan yang digunakan.

\section{METODE PELAKSANAAN PKM Permasalahan Prioritas}

Permasalahan utama dari SMP Santo Andreas adalah dibutuhkannya tenaga pengajar ekstrakurikuler di bidang Robotika yang terjangkau dengan materi ajar yang tepat dan efektif.

\section{Metode Pelaksanaan}

Pelaksanaan ekstrakurikuler yang diikuti 21 siswa SMP Santo Andreas dan akan dibuat 21 buah robot line tracking. Selain itu, pengajar akan membuat satu buah robot sebagai prototipe yang dapat dijadikan contoh. Alat dan bahan yang diperlukan pada setiap pertemuan dapat dilihat pada Tabel 1.

\section{Tabel 1}

Alat dan Bahan yang Diperlukan Setiap Pertemuan per Anak

\begin{tabular}{|c|c|c|c|}
\hline NO. & PERTEMUAN & NAMA & JUMLAH (PER SISWA) \\
\hline \multirow[t]{9}{*}{1.} & \multirow[t]{9}{*}{ PERTEMUAN 1} & Arduino NANO & $1 \mathrm{pcs}$ \\
\hline & & LED RGB & $5 \mathrm{pcs}$ \\
\hline & & BreadBoard & $1 \mathrm{pcs}$ \\
\hline & & Computer & $1 \mathrm{pcs}$ \\
\hline & & Baterai 9 volt & 2 pcs \\
\hline & & Resistor & 5 pcs \\
\hline & & Kapasitor & $5 \mathrm{pcs}$ \\
\hline & & Terminal listrik & $1 \mathrm{pcs}$ \\
\hline & & Kabel jumper male to male & 1 pack \\
\hline \multirow[t]{7}{*}{2.} & \multirow[t]{7}{*}{ PERTEMUAN 2} & Motor DC & $2 \mathrm{pcs}$ \\
\hline & & BreadBoard & $1 \mathrm{pcs}$ \\
\hline & & Kabel jumper male to male & 1 pack \\
\hline & & Arduino NANO & $1 \mathrm{pcs}$ \\
\hline & & Modul Dual H-Bridge & $1 \mathrm{pcs}$ \\
\hline & & Computer & $1 \mathrm{pcs}$ \\
\hline & & Resistor & 5 pcs \\
\hline
\end{tabular}




\begin{tabular}{|c|c|c|c|}
\hline & & Baterai 9 volt & $2 \mathrm{pcs}$ \\
\hline & & Terminal listrik & $5 \mathrm{pcs}$ \\
\hline \multirow[t]{9}{*}{3.} & \multirow[t]{9}{*}{ PERTEMUAN 3} & Arduino NANO & $1 \mathrm{pcs}$ \\
\hline & & Motor DC & $2 \mathrm{pcs}$ \\
\hline & & Kabel jumper male to male & 1 pack \\
\hline & & $L E D R G B$ & $5 \mathrm{pcs}$ \\
\hline & & BreadBoard & $1 \mathrm{pcs}$ \\
\hline & & Resistor & $5 \mathrm{pcs}$ \\
\hline & & Button & $5 \mathrm{pcs}$ \\
\hline & & Computer & $1 \mathrm{pcs}$ \\
\hline & & Baterai 9 volt & $2 \mathrm{pcs}$ \\
\hline \multirow[t]{8}{*}{4.} & \multirow[t]{8}{*}{ PERTEMUAN 4} & Arduino NANO & $1 \mathrm{pcs}$ \\
\hline & & Computer & $1 \mathrm{pcs}$ \\
\hline & & Modul Photo Dioda & $2 \mathrm{pcs}$ \\
\hline & & Kabel jumper male to male & 1 pack \\
\hline & & BreadBoard & $1 \mathrm{pcs}$ \\
\hline & & Resistor & $5 \mathrm{pcs}$ \\
\hline & & Kertas Warna Origami & 1 pak \\
\hline & & Baterai 9 volt & 2 pcs \\
\hline \multirow[t]{8}{*}{5.} & \multirow[t]{8}{*}{ PERTEMUAN 5} & Arduino NANO & $1 \mathrm{pcs}$ \\
\hline & & Computer & $1 \mathrm{pcs}$ \\
\hline & & LCD $2 \times 16$ & $1 \mathrm{pcs}$ \\
\hline & & BreadBoard & $1 \mathrm{pcs}$ \\
\hline & & Kabel jumper male to male & 1 pack \\
\hline & & Resistor & $5 \mathrm{pcs}$ \\
\hline & & Button & $5 \mathrm{pcs}$ \\
\hline & & Baterai 9 volt & $2 \mathrm{pcs}$ \\
\hline \multirow[t]{7}{*}{6.} & \multirow{7}{*}{ PERTEMUAN 6} & Arduino NANO & $1 \mathrm{pcs}$ \\
\hline & & Computer & $1 \mathrm{pcs}$ \\
\hline & & LCD $2 \times 16$ & $1 \mathrm{pcs}$ \\
\hline & & Kabel jumper male to male & 1 pack \\
\hline & & BreadBoard & $1 \mathrm{pcs}$ \\
\hline & & Resistor & $5 \mathrm{pcs}$ \\
\hline & & Modul Photo Dioda & 2 pcs \\
\hline \multirow[t]{16}{*}{7.} & \multirow[t]{16}{*}{ PERTEMUAN 7} & Kertas karton & 1 lembar \\
\hline & & Lem tembak & $1 \mathrm{pcs}$ \\
\hline & & Gunting & $1 \mathrm{pcs}$ \\
\hline & & Kabel Ties & $1 \mathrm{pak}$ \\
\hline & & Kabel jumper male to male & 1 pack \\
\hline & & Lem FOX & $1 \mathrm{pcs}$ \\
\hline & & Motor DC & 2 pcs \\
\hline & & BreadBoard & $1 \mathrm{pcs}$ \\
\hline & & Resistor & $5 \mathrm{pcs}$ \\
\hline & & Arduino NANO & $1 \mathrm{pcs}$ \\
\hline & & Modul Dual H-Bridge & $1 \mathrm{pcs}$ \\
\hline & & Computer & $1 \mathrm{pcs}$ \\
\hline & & Modul Photodioda & $2 \mathrm{pcs}$ \\
\hline & & LED RGB & $5 \mathrm{pcs}$ \\
\hline & & Cutter & $1 \mathrm{pcs}$ \\
\hline & & LCD $2 \times 16$ & $1 \mathrm{pcs}$ \\
\hline \multirow[t]{5}{*}{8.} & \multirow[t]{5}{*}{ PERTEMUAN 8} & Kertas karton & 1 lembar \\
\hline & & Motor dan gearbox beserta roda & $2 \mathrm{pcs}$ \\
\hline & & Lem tembak & $1 \mathrm{pcs}$ \\
\hline & & Ball caster & 2 pcs \\
\hline & & Gunting & $1 \mathrm{pcs}$ \\
\hline
\end{tabular}




\begin{tabular}{ll}
\hline Tombol on/off & $1 \mathrm{pcs}$ \\
\hline Kabel jumper male to male & $1 \mathrm{pack}$ \\
\hline Kabel Ties & $1 \mathrm{pak}$ \\
\hline Lem FOX & $1 \mathrm{pcs}$ \\
\hline Motor DC & $2 \mathrm{pcs}$ \\
\hline BreadBoard & $1 \mathrm{pcs}$ \\
\hline Resistor & $5 \mathrm{pcs}$ \\
\hline Arduino NANO & $1 \mathrm{pcs}$ \\
\hline Modul Dual H-Bridge & $1 \mathrm{pcs}$ \\
\hline Computer & $1 \mathrm{pcs}$ \\
\hline Modul Photodioda & $2 \mathrm{pcs}$ \\
\hline LED RGB & $5 \mathrm{pcs}$ \\
\hline Cutter & $1 \mathrm{pcs}$ \\
\hline LCD 2x16 & $1 \mathrm{pcs}$
\end{tabular}

\section{Jadwal Pelaksanaan}

Kegiatan ini diadakan setiap dua minggu sekali hari selasa dengan durasi 120 menit dari pukul 12.30-14.30 WIB. Kegiatan ekstrakurikuler diikuti oleh siswa Sekolah SMP Santo Andreas dari kelas VII dan VIII sejumlah 21 siswa. Pengajar merupakan mahasiswa teknik elektro Universitas Tarumanagara sebanyak 4 orang. pada pertemuan ke-2 sampai ke- 8 terjadi penambahan waktu dikarenakan materi yang diajarkan tidak dapat diserap oleh siswa dengan cepat. Silabus pengajaran yang akan dilaksanakan pada SMP Santo Andreas dalam 1 semester dapat dilihat pada Tabel 2.

Tabel 2

Silabus Pengajaran Selama Satu Semester

\begin{tabular}{|c|c|c|c|c|}
\hline PERTEMUAN & $\begin{array}{c}\text { PROGRAM } \\
\text { MATERI }\end{array}$ & TUJUAN AKHIR & BAHAN & PROYEK AKHIR \\
\hline \multirow[t]{4}{*}{ PERTEMUAN KE 1} & \multirow{4}{*}{$\begin{array}{l}\text { ARDUINO } \\
\text { NANO }\end{array}$} & \multirow{4}{*}{$\begin{array}{l}\text { Pengenalan Arduino } \\
\text { Nano } \\
\text { menyalakan LED } \\
\text { RGB dengan Arduino } \\
\text { Nano }\end{array}$} & Arduino NANO & Di lapangan \\
\hline & & & LED RGB & \multirow{3}{*}{$\begin{array}{l}\text { Praktek } \\
\text { Menghidupkan } \\
\text { LED }\end{array}$} \\
\hline & & & BreadBoard & \\
\hline & & & Computer; dll & \\
\hline \multirow[t]{5}{*}{ PERTEMUAN KE 2} & \multirow[t]{5}{*}{$\begin{array}{l}\text { MOTOR DC } \\
\text { GEARBOX }\end{array}$} & \multirow{5}{*}{$\begin{array}{l}\text { Menggunakan } \\
\text { Arduino untuk } \\
\text { Menghidupkan Motor } \\
\text { DC Menggunakan } \\
\text { Speed Controller } \\
\text { Modul Dual H-Bridge }\end{array}$} & $\begin{array}{l}\text { Motor DC; 9V } \\
\text { baterai }\end{array}$ & Di lapangan \\
\hline & & & BreadBoard & \multirow{4}{*}{$\begin{array}{l}\text { Praktek } \\
\text { Menghidupkan } \\
\text { Motor } \\
\text { dan mengatur } \\
\text { kecepatan motor }\end{array}$} \\
\hline & & & Arduino NANO & \\
\hline & & & $\begin{array}{l}\text { Modul Dual H- } \\
\text { Bridge }\end{array}$ & \\
\hline & & & Computer; dll & \\
\hline \multirow[t]{6}{*}{ PERTEMUAN KE 3} & \multirow[t]{6}{*}{ BUTTON PAD } & \multirow{6}{*}{$\begin{array}{l}\text { Menggunakan Button } \\
\text { sebagai Input ke } \\
\text { Arduino }\end{array}$} & Arduino NANO & \multirow{6}{*}{$\begin{array}{l}\text { Di lapangan, } \\
\text { Praktek Merangkai } \\
\text { Button menjadi } \\
\text { suatu fungsi input } \\
\text { kendali keluaran } \\
\text { yang berbeda beda }\end{array}$} \\
\hline & & & $\begin{array}{l}\text { Motor DC; 9V } \\
\text { baterai }\end{array}$ & \\
\hline & & & LED RGB & \\
\hline & & & BreadBoard & \\
\hline & & & Button & \\
\hline & & & Computer; dll & \\
\hline \multirow[t]{3}{*}{ PERTEMUAN KE 4} & \multirow[t]{3}{*}{ SENSOR GARIS } & \multirow{3}{*}{$\begin{array}{l}\text { Mengenal Sensor } \\
\text { garis untuk } \\
\text { ditampilkan pada } \\
\text { Computer }\end{array}$} & Arduino NANO & \multirow{3}{*}{$\begin{array}{l}\text { Di lapangan } \\
\text { menggunakan } \\
\text { komputer sebagai } \\
\text { fungsi keluaran }\end{array}$} \\
\hline & & & $\begin{array}{l}\text { Computer; } \\
\text { Baterai 9v }\end{array}$ & \\
\hline & & & $\begin{array}{l}\text { Modul Photo } \\
\text { Dioda }\end{array}$ & \\
\hline
\end{tabular}




\begin{tabular}{|c|c|c|c|c|}
\hline & & & BreadBoard & \multirow{2}{*}{$\begin{array}{l}\text { untuk mendeteksi } \\
\text { warna }\end{array}$} \\
\hline & & & $\begin{array}{l}\text { Kertas Warna } \\
\text { Origami; dll }\end{array}$ & \\
\hline \multirow[t]{5}{*}{ PERTEMUAN KE 5} & \multirow[t]{5}{*}{ LCD } & \multirow{5}{*}{$\begin{array}{l}\text { Mengenal Modul } \\
\text { Penampil LCD } \\
\text { sebagai penampil } \\
\text { layar }\end{array}$} & Arduino NANO & \multirow{5}{*}{$\begin{array}{l}\text { Di lapangan, } \\
\text { Menggunakan LCD } \\
\text { sebagai penampil } \\
\text { layar menggunakan } \\
\text { arduino NANO }\end{array}$} \\
\hline & & & Computer & \\
\hline & & & LCD $2 \times 16$ & \\
\hline & & & BreadBoard & \\
\hline & & & Button; dll & \\
\hline \multirow[t]{5}{*}{ PERTEMUAN KE 6} & \multirow{5}{*}{$\begin{array}{l}\text { LINE } \\
\text { DETECTOR }\end{array}$} & \multirow{5}{*}{$\begin{array}{l}\text { Mengajarkan } \\
\text { bagaimana } \\
\text { mendeteksi warna } \\
\text { garis yang akan } \\
\text { diikuti dan } \\
\text { ditampilkan ke dalam } \\
\text { LCD menggunakan } \\
\text { Arduino NANO }\end{array}$} & Arduino NANO & \multirow{5}{*}{$\begin{array}{l}\text { Di Lapangan, } \\
\text { menggunakan } \\
\text { sensor garis untuk } \\
\text { di fungsikan ke } \\
\text { fungsi pembaca } \\
\text { garis }\end{array}$} \\
\hline & & & Computer & \\
\hline & & & LCD $2 \times 16$ & \\
\hline & & & BreadBoard & \\
\hline & & & $\begin{array}{l}\text { Modul Photo } \\
\text { Dioda; dll }\end{array}$ & \\
\hline \multirow[t]{4}{*}{ PERTEMUAN KE 7} & \multirow{4}{*}{$\begin{array}{l}\text { DESAIN BASE } \\
\text { PLAT }\end{array}$} & \multirow{4}{*}{$\begin{array}{l}\text { Belajar Mendesain } \\
\text { dan merancang bentuk } \\
\text { mobil yang } \\
\text { diinginkan. }\end{array}$} & Kertas karton & \multirow{4}{*}{$\begin{array}{l}\text { Di Lapangan, } \\
\text { menggunakan } \\
\text { peralatan untuk } \\
\text { melakukan seni } \\
\text { desain membuat } \\
\text { robot Line Follower } \\
\text { sesuai dengan } \\
\text { fungsional sensor, } \\
\text { elektronika lainnya. }\end{array}$} \\
\hline & & & $\begin{array}{l}\text { Gunting, Cutter, } \\
\text { dll } \\
\text { Kabel Ties }\end{array}$ & \\
\hline & & & Lem FOX & \\
\hline & & & $\begin{array}{l}\text { Komponen di } \\
\text { pertemuan 1-6 }\end{array}$ & \\
\hline \multirow[t]{8}{*}{ PERTEMUAN KE 8} & \multirow{8}{*}{$\begin{array}{l}\text { LINE } \\
\text { FOLLOWER }\end{array}$} & \multirow{8}{*}{$\begin{array}{l}\text { mengajarkan } \\
\text { merangkai semua } \\
\text { fungsi menjadi suatu } \\
\text { robot pengikut garis } \\
\text { dengan menggunakan } \\
\text { materi pengajaran dari } \\
\text { pertemuan ke } 1 \\
\text { hingga ke pertemuan } \\
\text { ke } 7\end{array}$} & Arduino NANO & \multirow[t]{8}{*}{ Robot tracker } \\
\hline & & & Computer & \\
\hline & & & LCD $2 \times 16$ & \\
\hline & & & BreadBoard & \\
\hline & & & LED RGB & \\
\hline & & & Button & \\
\hline & & & $\begin{array}{l}\text { Motor DC 9V } \\
\text { baterai }\end{array}$ & \\
\hline & & & $\begin{array}{l}\text { Modul Photo } \\
\text { Dioda; dll }\end{array}$ & \\
\hline
\end{tabular}

\section{HASIL DAN PEMBAHASAN}

Kegiatan pemberian edukasi berupa ekstrakurikuler robotika dengan robot line tracker kepada mitra telah selesai dilakukan. Adapun yang telah dilakukan yaitu pada tiap pertemuan dapat dilihat pada Tabel 3.

\section{Tabel 3}

Hasil Kegiatan Ekstrakurikuler Pada Sekolah Smp Santo Andreas

\begin{tabular}{|c|c|c|c|}
\hline NO. & PERTEMUAN & TARGET MATERI & REALISASI DI LAPANGAN \\
\hline 1. & Pertemuan ke-1 & $\begin{array}{ll}\text { - } & \text { Pengenalan tentang elektro } \\
\text { - } & \text { Pengenalan arduino nano } \\
\text { - } & \text { Pengenalan bahasa pemrograman } \\
\text { - } & \text { Pemograman arduino nano } \\
& \text { dengan aplikasi arduino IDE } \\
\text { untuk menyalakan LED RGB }\end{array}$ & $\begin{array}{ll}- & \text { Pengenalan tentang elektro } \\
\text { - } & \text { Pengenalan arduino nano } \\
\text { - } & \text { Pengenalan bahasa pemrograman } \\
\text { - } & \text { Pemograman arduino nano } \\
& \text { dengan aplikasi arduino IDE } \\
& \text { untuk menyalakan LED RGB }\end{array}$ \\
\hline
\end{tabular}




\begin{tabular}{|c|c|c|c|}
\hline 2. & Pertemuan ke-2 & 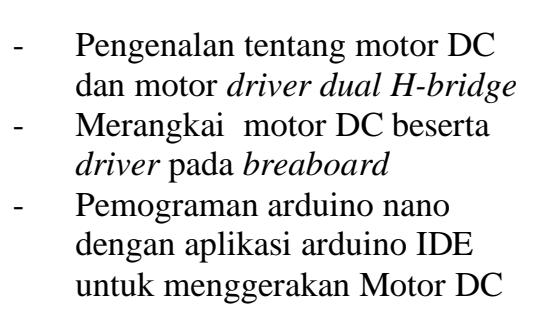 & $\begin{array}{ll}\text { - } & \text { Pengenalan tentang elektro } \\
\text { - } & \text { Pengenalan arduino nano } \\
\text { - } & \text { Pengenalan bahasa pemrograman } \\
\text { - } & \text { Pemograman arduino nano } \\
& \text { dengan aplikasi arduino IDE } \\
& \text { untuk menyalakan LED RGB } \\
\text { - } & \text { Terjadi penambahan waktu } \\
& \text { sebanyak } 10 \text { menit }\end{array}$ \\
\hline 3. & Pertemuan ke-3 & $\begin{array}{ll}\text { - } & \text { Pengenalan tentang button dan } \\
\text { button pad } \\
\text { - } & \text { Merangkai button menjadi } \\
\text { sebuah rangkaian button pad. } \\
\text { - } \quad \text { Pemograman arduino nano } \\
\text { dengan aplikasi arduino IDE } \\
\text { untuk membuat button pad } \\
\text { menjadi sebuah input kondisi } \\
\text { (menggunakan LED) }\end{array}$ & $\begin{array}{ll}\text { - } & \text { Pengenalan tentang button dan } \\
\text { button pad } \\
\text { - }\end{array}$ \\
\hline 4. & Pertemuan ke-4 & $\begin{array}{ll}\text { - } & \text { Pengenalan tentang sensor garis } \\
\text { - } & \text { Pengenalan tentang serial } \\
\text { monitor pada aplikasi Arduino } \\
\text { IDE } \\
\text { - } \quad \text { Pengenalan bahasa pemrograman } \\
\text { - } \quad \text { Mondisi ( IF ELSE) } \\
\text { breangkai sensor garis pada } \\
\text { - } \quad \text { Pemograman arduino nano } \\
\text { dengan aplikasi arduino IDE } \\
\text { untuk membaca nilai sensor garis } \\
\text { dan ditampilkan pada serial } \\
\text { monitor }\end{array}$ & $\begin{array}{ll}\text { - } & \text { Pengenalan tentang sensor garis } \\
\text { - } & \text { Pengenalan tentang serial } \\
\text { monitor pada aplikasi Arduino } \\
\text { IDE } \\
\text { - } \quad \text { Pengenalan bahasa pemrograman } \\
\text { kondisi ( IF ELSE) } \\
\text { - } \quad \text { Merangkai sensor garis pada } \\
\text { breadboard } \\
\text { - } \quad \text { Pemograman arduino nano } \\
\text { dengan aplikasi arduino IDE } \\
\text { untuk membaca nilai sensor garis } \\
\text { dan ditampilkan pada serial } \\
\text { monitor } \\
\text { Terjadi penambahan waktu } \\
\text { sebanyak } 10 \text { menit }\end{array}$ \\
\hline 5. & Pertemuan ke-5 & 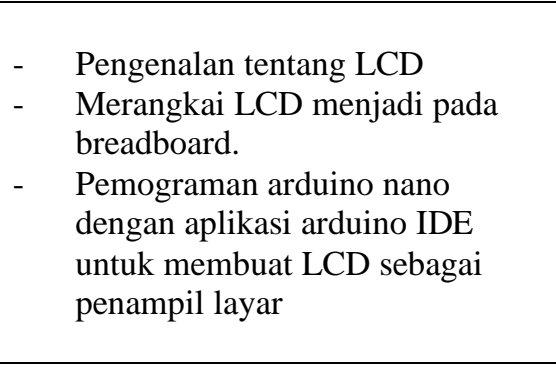 & $\begin{array}{ll}\text { - } & \text { Pengenalan tentang LCD } \\
\text { - } & \text { Merangkai LCD menjadi pada } \\
\text { breadboard. } \\
\text { - } \quad \text { Pemograman arduino nano } \\
\text { dengan aplikasi arduino IDE } \\
\text { untuk membuat LCD sebagai } \\
\text { penampil layar } \\
\text { - Terjadi penambahan waktu } \\
\text { sebanyak } 5 \text { menit }\end{array}$ \\
\hline 6. & Pertemuan ke-6 & $\begin{array}{l}\text { - Merangkai dan menggabungkan } \\
\text { LCD dan sensor garis pada } \\
\text { breadboard } \\
\text { Pemograman arduino nano } \\
\text { dengan aplikasi arduino IDE } \\
\text { untuk menampilkan nilai yang } \\
\text { didapat oleh sensor garis dalam } \\
\text { LCD }\end{array}$ & 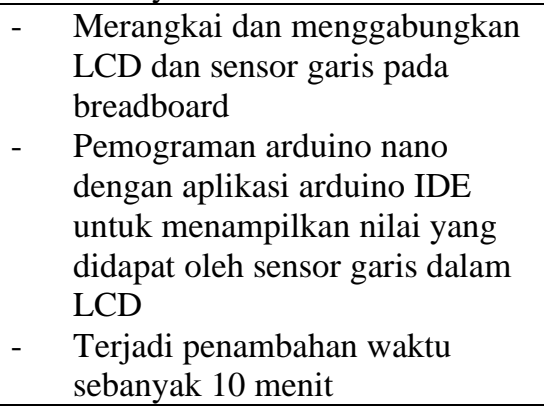 \\
\hline 7. & Pertemuan ke-7 & $\begin{array}{ll}\text { - } & \text { Pengenalan tentang dasar desain } \\
\text { robot } \\
\text { - } \\
\text { Merancang desain fisik dari robot } \\
\text { line tracking }\end{array}$ & $\begin{array}{ll}\text { - } & \text { Pengenalan tentang dasar desain } \\
\text { robot } \\
\text { - } \\
\text { Merancang desain fisik dari robot } \\
\text { line tracking }\end{array}$ \\
\hline
\end{tabular}




\begin{tabular}{|c|c|c|c|c|}
\hline & & & $\begin{array}{l}\text { Merangkai desain fisik dan } \\
\text { mekanik dari robot line tracking }\end{array}$ & $\begin{array}{ll}\text { - } & \text { Merangkai desain fisik dan } \\
\text { mekanik dari robot line tracking } \\
\text { - } \\
\text { Terjadi penambahan waktu } \\
\text { sebanyak } 15 \text { menit }\end{array}$ \\
\hline 8. & Pertemuan ke- 8 & - & $\begin{array}{l}\text { Merangkai seluruh komponen } \\
\text { penyusun robot line tracking } \\
\text { menjadi sebuah robot utuh } \\
\text { Pemrograman arduino nano } \\
\text { dengan aplikasi arduino IDE } \\
\text { robot line tracking agar menjadi } \\
\text { robot yang fungsional }\end{array}$ & $\begin{array}{l}\text { Merangkai seluruh komponen } \\
\text { penyusun robot line tracking } \\
\text { menjadi sebuah robot utuh } \\
\text { - Pemrograman arduino nano } \\
\text { dengan aplikasi arduino IDE } \\
\text { robot line tracking agar menjadi } \\
\text { robot yang fungsional } \\
\text { Terjadi penambahan waktu } \\
\text { sebanyak } 20 \text { menit }\end{array}$ \\
\hline
\end{tabular}

Foto-foto kegiatan ekstrakurikuler ini dapat dilihat pada Gambar 2, Gambar 3 dan Gambar 4. Gambar 2 memperlihatkan salah satu pengajar yang sedang memberikan penjelasan mengenai komponen-komponen dasar elektronika yang akan dimanfaatkan dalam kegiatan. Gambar 3 memperlihatkan pengajar yang sedang memperlihatkan slide dan menjelaskan tentang controller dan driver. Gambar 4 memperlihatkan suasana kegiatan belajar para siswa dalam kegiatan ini.

\section{Gambar 2}

Penjelasan Tentang Komponen Dasar Elektronika

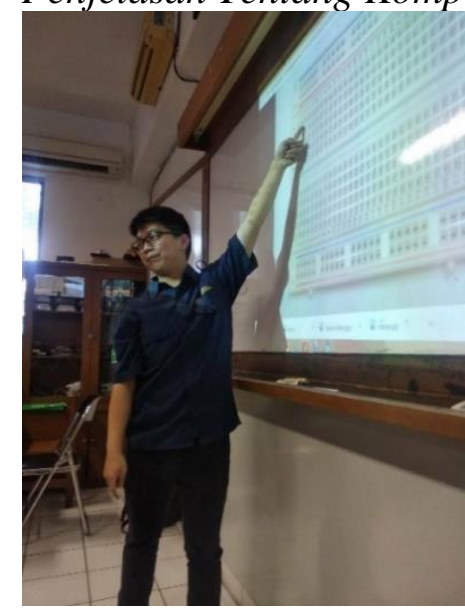

\section{Gambar 3}

Penjelasan Tentang Speed Controller Modul Dual H-Bridge

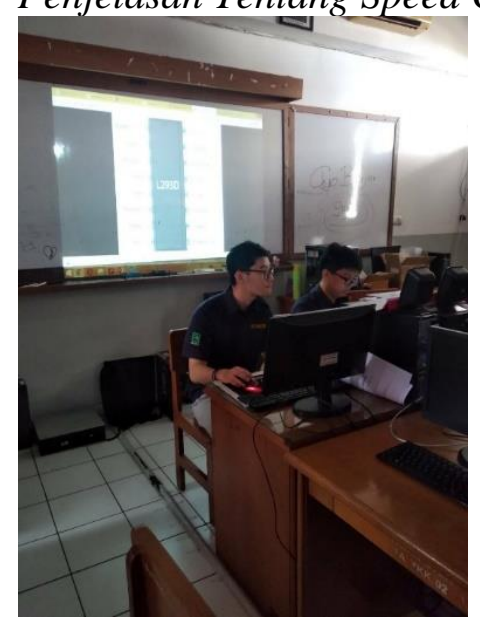




\section{Gambar 4}

Suasana Kegiatan Ekstrakurikuler Pada Pertemuan Ketiga

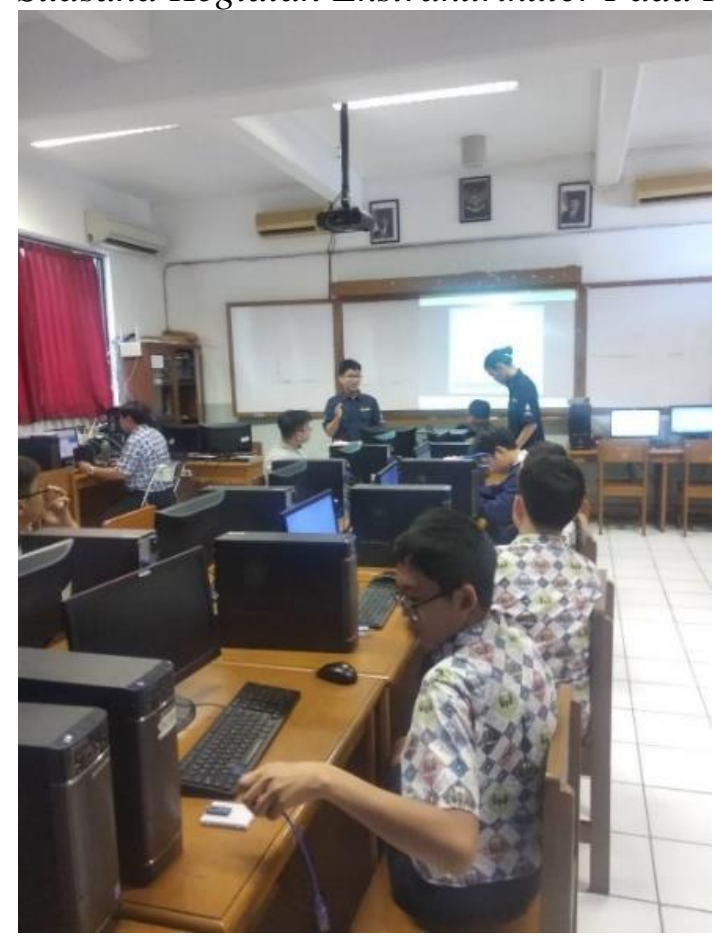

\section{KESIMPULAN DAN SARAN}

Diperlukan durasi lebih panjang pada setiap pertemuan dari kegiatan ekstrakurikuler sehingga materi dan target pengajaran yang diberikan menjadi lebih tersampaikan dengan baik. Dibutuhkannya tambahan pengajar agar kegiatan ekstrakurikuler lebih terkontrol. Hal ini dikarenakan rasio perbandingan peserta dan pengajar sebesar 21:4 dan materi yang diajarkan memerlukan pendampingan lebih dari para pengajar, sementara jumlah pengajar yang kurang menyebabkan beberapa materi tidak tersampaikan dengan baik. Melihat antusiasme peserta kegiatan ekstrakurikuler robotika line tracking robot ini sangat tinggi, perlu dijadikan kegiatan tetap atau menjadi mata pelajaran dalam kurikulum pendidikan dari Sekolah SMP Santo Andreas.

\section{REFERENSI}

Jatmiko, et al. (2012). Robotika: Teori dan aplikasi. UI PRESS.

Nalwan, A. (2012). Teknik rancang bangun robot. Penerbit ANDI.

Romadhon, A. S., \& Fuad, M. (2013). Perancangan sistem kontrol gerakan pada robot line tracking. Jurnal Mikrotek, 1(1). https://journal.trunojoyo.ac.id/jim/article/view/167

Tridhonanto, Al. (2010). Meraih sukses dengan kecerdasan emosional. Gramedia.

Winarno \& Arifianto, D. (2011). Bikin robot itu gampang. Kawasan Pustaka 